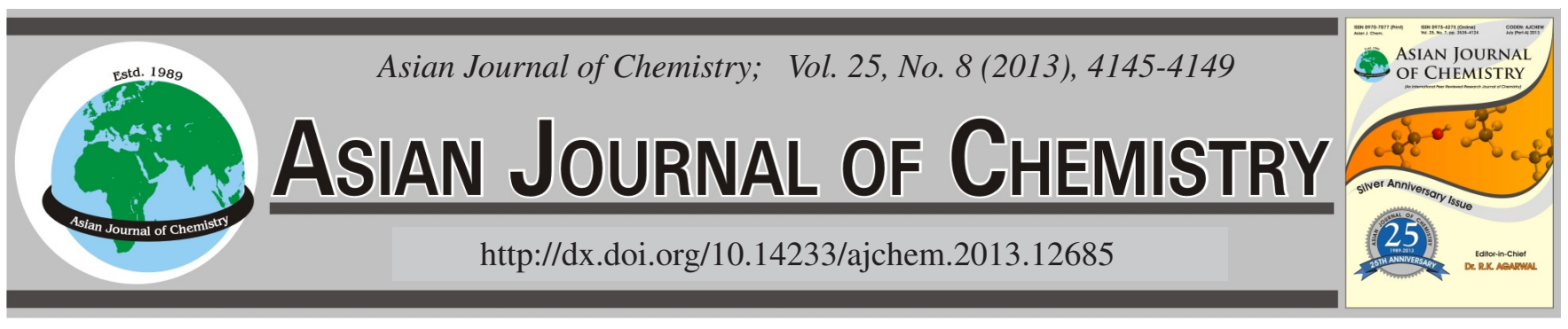

\title{
Polyaniline Nano Composite for the Adsorption of Reactive Dye from Aqueous Solutions: Equilibrium and Kinetic Studies
}

\author{
J. RAfFiea Baseri ${ }^{1, *}$, P.N. Palanisamy ${ }^{2}$ and P. Sivakumar ${ }^{3}$
}

${ }^{1}$ Department of Chemistry, Al-Ameen Engineering College, Erode-638 104, India

${ }^{2}$ Department of Chemistry, Kongu Engineering College, Perundurai, Erode-638 052, India

${ }^{3}$ Department of Chemistry, Arignar Anna Government Arts College, Namakkal-637 002, India

*Corresponding author: E-mail: raffiea2010@gmail.com

(Received: 20 January 2012;

Accepted: 4 February 2013)

AJC-12914

In the present study, polyaniline nano composite was synthesized through direct chemical polymerization. Polyaniline nano composite
was tested for the removal of reactive dye, reactive orange 4 from aqueous solutions by batch adsorption technique under varying
conditions of agitation time, dye concentration, $\mathrm{pH}$ and temperature. Lower solution $\mathrm{pH}(3$ to 5$)$ favoured the adsorption of reactive dye
onto polyaniline nano composite. The dye adsorption increases from 45.83 to $143.59 \mathrm{mg} / \mathrm{g}$ on increasing the initial concentration from 25
to $100 \mathrm{mg} / \mathrm{L}$. The pseudo second order kinetic model adequately described the kinetics of dye adsorption with high correlation coefficient
$(0.99)$. Langmuir isotherm model well fitted to the experimental data. Thermodynamic parameters like free energy $\left(\Delta \mathrm{G}^{\circ}\right)$, enthalpy $\left(\Delta \mathrm{H}^{\circ}\right)$
and entropy $\left(\Delta \mathrm{S}^{\circ}\right)$ were also calculated. Maximum desorption of $78.6 \%$ for reactive orange 4 was observed at a pH range of 8 to 9 . The
results indicated that polyaniline nano composite is a promising adsorbent for the removal of dyes from aqueous solution.

Key Words: Polyaniline composites, Reactive orange 4, Removal, Kinetics, Isotherms.

ᄂ _ _ - - - - - - - - - - - - - - - - - - - - - - - - - - -

\section{INTRODUCTION}

The wastewater treatment has been a main problem of the textile industry for long time. These effluents contain various kinds of synthetic dyestuffs. Owing to the good solubility, synthetic dyes are common water pollutants and they are frequently found in trace quantities in industrial wastewater ${ }^{1}$. Dyes may have chronic and acute effects on living organisms, affect the nature of water and inhibit sunlight penetration into the stream which reduces photosynthesis ${ }^{2}$.

Reactive dyes are extensively used in dyeing process. However about 10 to $40 \%$ of these dyes remain in the effluent $t^{3,4}$. Because of the more solubility of reactive dyes, removal from wastewater is difficult by conventional coagulation and the activated sludge process ${ }^{5}$. Adsorption is an effective treatment method that is widely used for the removal of contaminants from water and wastewater. This method has also been proven to be an important way to treat coloured effluents ${ }^{6}$.

Activated carbon is the most commonly used adsorbent due to its high adsorption capacity ${ }^{7}$. However the high cost of activated carbon restricts its use largely in developing countries. This has led many researchers to search for the use of low cost and efficient alternative materials such as $\mathrm{coal}^{8}$, fly ash ${ }^{9}$, rice husk $^{10}$, bagasse pith ${ }^{11}$, date pits ${ }^{12}$, fruit stones and nutshells ${ }^{13}$.
However very little data are available on the adsorption kinetics of sawdust.

In this study, polyaniline nano composite synthesized chemically on the surface of sawdust from aqueous bronsted acid solutions. Chemical polymerization of aniline in aqueous acidic media can be easily performed using of oxidizing agents such as $\left(\mathrm{NH}_{4}\right)_{2} \mathrm{~S}_{2} \mathrm{O}_{8}$. Polyaniline nano composite used for the removal of reactive orange 4 from aqueous solution.

\section{EXPERIMENTAL}

Adsorbate: The dye used in this study was reactive orange 4 having molecular formula $\mathrm{C}_{24} \mathrm{H}_{13} \mathrm{~N}_{6} \mathrm{O}_{10} \mathrm{~S}_{3} \mathrm{Na}_{3} \mathrm{Cl}_{2}$ (m.w. 781.46) with CI No. 18260. The molecular structure is given in Fig. 1. All the chemicals used were high purity, commercially available analar grade. A stock solution of $1000 \mathrm{mg} / \mathrm{L}$ was prepared by dissolving appropriate amount of dye (based on percentage purity) in $1 \mathrm{~L}$ of double distilled water. The experimental solutions were obtained by diluting the dye stock solutions in accurate proportions to different initial concentrations.

Adsorbent: Polyaniline composite was synthesized on sawdust surface of Thevetia peruviana. In order to prepare polymer coated sawdust, $5 \mathrm{~g}$ sawdust immersed in $50 \mathrm{~mL}$ of $0.20 \mathrm{M}$ freshly distilled aniline in $1 \mathrm{M} \mathrm{HCl}$ solution for $6 \mathrm{~h}$ 
<smiles>CN(c1ccc2c(O)c(N=Nc3ccc4c(S(=O)(=O)O)cccc4c3S(=O)(=O)O)c(S(=O)(=O)O)cc2c1)c1nc(Cl)nc(Cl)n1</smiles>

Fig. 1. Molecular structure of reactive orange 4

before polymerization. The excess of the monomer solution was removed by simple decantation. Then $50 \mathrm{~mL}$ of $0.5 \mathrm{M}$ $\left(\mathrm{NH}_{4}\right)_{2} \mathrm{~S}_{2} \mathrm{O}_{8}$ as an oxidant solution was added into the mixture gradually and the reaction was allowed to continue for $4 \mathrm{~h}$ at room temperature. The polymer coated sawdust (polyaniline nano composite) was filtered, washed with distilled water, dried in an oven at $c a .60{ }^{\circ} \mathrm{C}$ and sieved before use $\mathrm{e}^{14}$. The coating percentage of each polymer onto saw dust determined by weight difference of the dried sawdust before and after coating and it was nearly $5 \%$. The characteristics of the polyaniline nano composite were studied as per the standard procedures ${ }^{15,16}$ and the surface morphology was analyzed by scanning electron microscope images.

Batch mode adsorption experiments: The adsorption experiments were carried out by agitating $100 \mathrm{mg}$ adsorbent with $200 \mathrm{~mL}$ of dye solutions of 25 to $100 \mathrm{mg} / \mathrm{L}$ concentration at $150 \mathrm{rpm}$ on an orbital shaker (REMI make). The mixture was withdrawn at specified intervals, centrifuged using electrical centrifuge (Universal make) at $5000 \mathrm{rpm}$ for $20 \mathrm{~min}$ and unadsorbed supernatant liquid was analyzed for the residual dye concentration using Elico make UV spectrophotometer (CI 73) at $479 \mathrm{~nm}$. The effect of $\mathrm{pH}$ was studied by using dilute $\mathrm{HCl}$ and $\mathrm{NaOH}$ solutions. The effect of temperature was studied at four different temperatures $\left(30,35,40\right.$ and $\left.45^{\circ} \mathrm{C}\right)$. All experiments were carried out in duplicate and the mean values are reported, where the maximum deviation was within $4 \%$.

The amount of dye adsorbed on polyaniline nano composite was calculated from the following equation:

$$
\mathrm{q}_{\mathrm{t}}=\frac{\left(\mathrm{C}_{0}-\mathrm{C}_{\mathrm{e}}\right)}{\mathrm{M}} \mathrm{V}
$$

where, $\mathrm{q}_{\mathrm{t}}(\mathrm{mg} / \mathrm{g})$ is the amount of dye adsorbed at time $\mathrm{t}, \mathrm{C}_{0}$ and $\mathrm{C}_{\mathrm{e}}(\mathrm{mg} / \mathrm{L})$ are the concentrations of dye at initial and equilibrium, respectively. $\mathrm{V}(\mathrm{L})$ is the volume of dye solution and $\mathrm{W}(\mathrm{g})$ is the mass of dry adsorbent.

Desorption studies: Desorption studies were carried out to analyze the mechanism of adsorption and recovery of the adsorbate and adsorbent. The supernatant was separated after centrifugation and the adsorbent was separated and allowed to agitate with $100 \mathrm{~mL}$ of distilled water at different $\mathrm{pH}$ (211) above the equilibrium time of adsorption. The desorbed dye solution was estimated as given in the adsorption studies ${ }^{17}$.

\section{RESULTS AND DISCUSSION}

Characterization studies: The characteristics of polyaniline nano composite are presented in Table-1. It can be seen from the SEM micrograph (Fig. 2) of sawdust-PPy composite that the surface of sawdust is coated with polyaniline nano composites aggregated in clusters having globular particle shape with an average diameter of about $100 \mathrm{~nm}^{18}$.

\begin{tabular}{clc}
\multicolumn{3}{c}{ TABLE-1 } \\
& \multicolumn{2}{c}{$\begin{array}{c}\text { PHYSICO-CHEMICAL CHARACTERISTICS OF } \\
\text { POLYANILINE NANO COMPOSITE (PAC) }\end{array}$} \\
\hline S. No. & \multicolumn{1}{c}{ Properties } & PAC \\
\hline 1 & $\mathrm{pH}$ & 7.42 \\
2 & Conductivity $\left(\mathrm{mS} / \mathrm{cm}^{2}\right)$ & 5.93 \\
3 & Methylene blue number $(\mathrm{mg} / \mathrm{g})$ & 45 \\
4 & Iodine number $(\mathrm{mg} / \mathrm{g})$ & 87 \\
5 & Volatile matter $(\%)$ & 56.3 \\
\hline
\end{tabular}

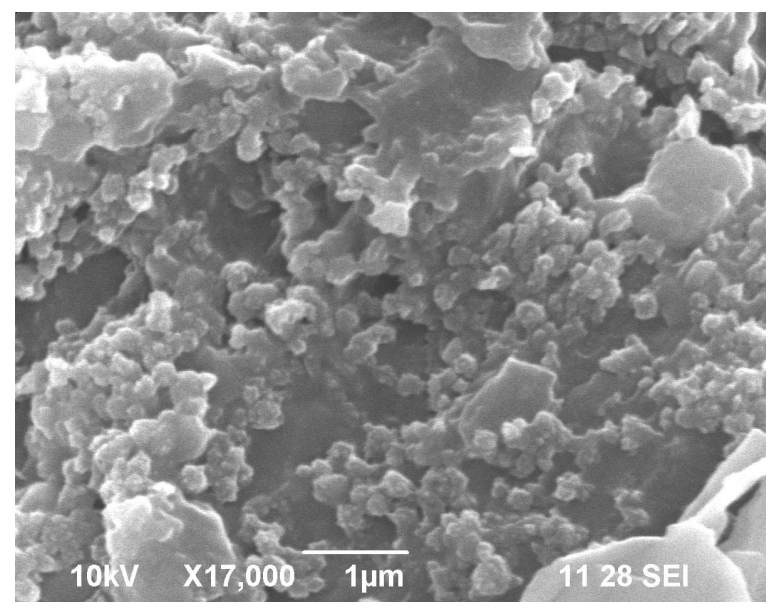

Fig. 2. Scanning electron microscope of polyaniline nano composite

Effect of agitation time and initial dye concentration: The effect of time on the removal of reactive orange 4 by polyaniline nano composite is shown in Fig. 3. The percentage of removal increases with time and attains equilibrium at 50 min for all concentrations studied ( 25 to $100 \mathrm{mg} / \mathrm{L}$ ). After that no significant change was observed in the extent of adsorption. The amount of dye adsorption increases from 45.83 to $143.59 \mathrm{mg} / \mathrm{g}$ while increasing the initial dye concentration from 25 to $100 \mathrm{mg} / \mathrm{L}$. This is due to the fact that with increase in dye concentration, the presence of dye molecules near the adsorbent also increased. Similar results were reported for the adsorption of textile reactive dye using Posidonia oceanica (L) fibrous mass ${ }^{19}$.

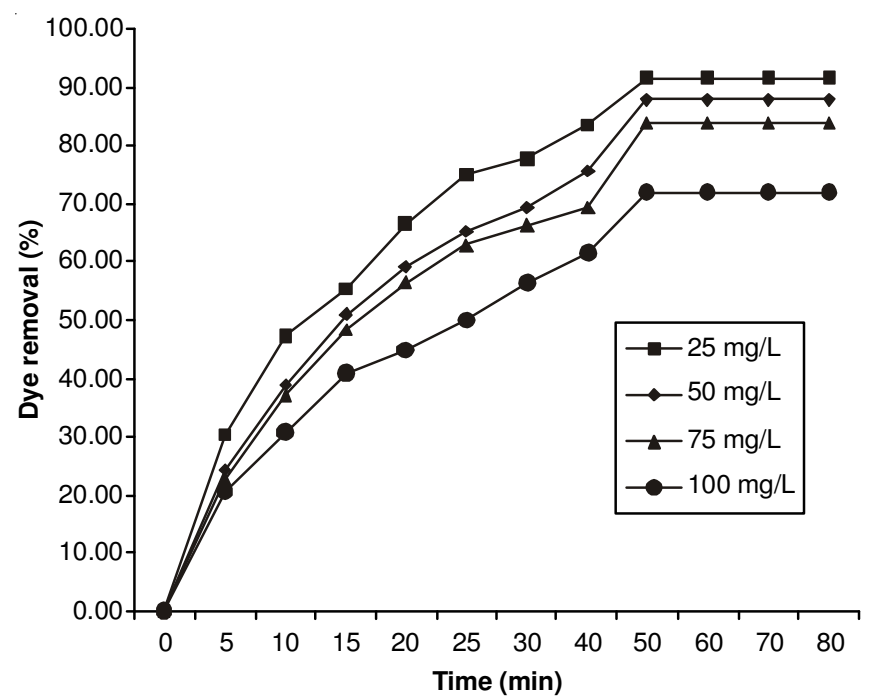

Fig. 3. Effect of agitation time on the percentage removal of reactove pramge 4 dye on polyaniline nano composite at $30{ }^{\circ} \mathrm{C}$ (adsorbent dosage, $100 \mathrm{mg}$; $\mathrm{pH}, 4.1$ ) 
Polyaniline nano composite has positively fixed charged sites which are balanced with the anions $\left(\mathrm{Cl}^{-}\right.$ions $)$originating from monomer or oxidant solution during their synthesis. The small size dopant anions can be exchanged with other anionic species in treated solutions which have stronger interactions with the polymer ${ }^{14}$. It may be suggested that the rate of anionic dye removal is high due to the ion exchange mechanism between mobile $\mathrm{Cl}^{-}$ions and anionic dye molecules.

Effect of pH: It is found that the percentage removal of reactive orange 4 was higher when the $\mathrm{pH}$ is below 5. Above the $\mathrm{pH} 5$, the adsorption rate decreased. In acidic conditions, the surface of the adsorbent is positively charged due to high concentration of $\mathrm{H}^{+}$, so electrostatic attraction between the adsorbent and the adsorbate (anionic dye) is enhanced. Lower adsorption of reactive orange 4 under alkaline conditions is due to the presence of hydroxyl ions on the surface of adsorbents competing with the adsorbate for adsorption sites ${ }^{20}$.

Effect of temperature: It has been observed from Fig. 4 that the percentage removal of reactive orange 4 by polyaniline nano composite increases from 87.76 to $97.96 \%$ on increasing the temperature from 30 to $45{ }^{\circ} \mathrm{C}$. This indicates that the sorption of anionic dyes is endothermic in nature ${ }^{21}$. These adsorption data were further analyzed with adsorption isotherm models to find out the suitable model.

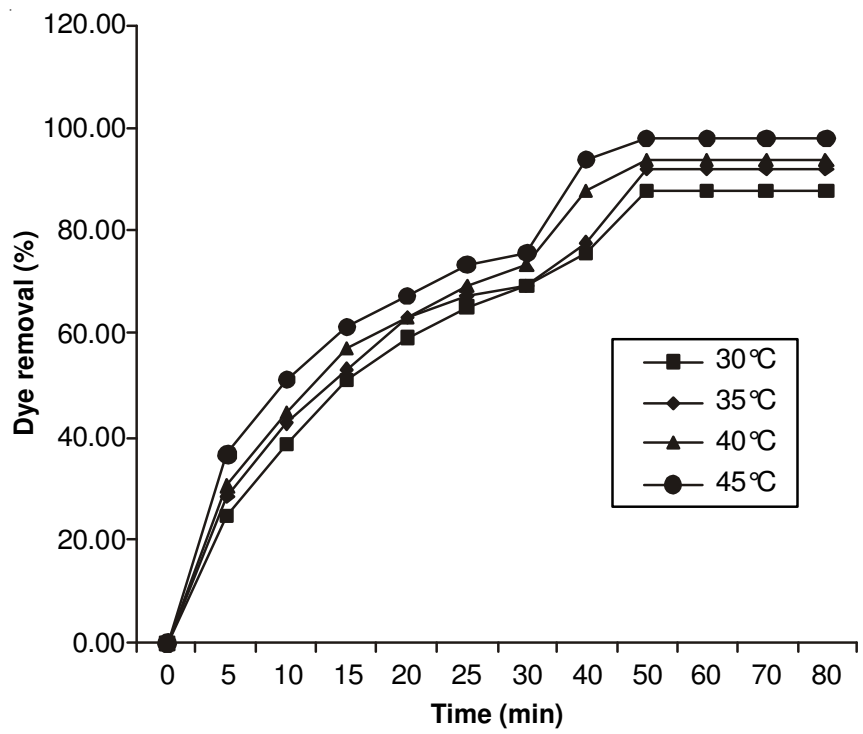

Fig. 4. Effect of temperature on the adsorption of reactive orange 4 dye on to polyaniline nano composite at initial concentration of $50 \mathrm{mg} / \mathrm{L}$ (adsorbent dosage, 100 mg; pH, 4.1)
Adsorption kinetics: Adsorption kinetics is necessary for the design of adsorption systems ${ }^{22}$. In present study, the following two kinetic models were applied for the experimental data.

Pseudo first-order kinetic model assumes that the rate of change of solute uptake with time is directly proportional to difference in saturation concentration and the amount of solid uptake with time ${ }^{23}$. The rate constant of adsorption is expressed as a first - order rate expression given as:

$$
\log \left(\mathrm{q}_{\mathrm{e}}-\mathrm{q}_{\mathrm{t}}\right)=\log \mathrm{q}_{\mathrm{e}}-\frac{\mathrm{k}_{1}}{2.303} \mathrm{t}
$$

where, $\mathrm{k}_{1}$ is the pseudo-first-order rate constant $\left(\mathrm{min}^{-1}\right)$.

The plot of $\log \left(\mathrm{q}_{\mathrm{e}}-\mathrm{q}_{\mathrm{t}}\right)$ versus $\mathrm{t}$ should give a straight line with slope of $-\mathrm{k}_{1} / 2.303$ and intercept $\log \mathrm{q}_{\mathrm{e}}$ which allows calculation of adsorption rate constant $\mathrm{k}_{1}$ and equilibrium adsorption capacity $\mathrm{q}_{\mathrm{e}}$. Calculated values of $\mathrm{k}_{1}$ and $\mathrm{q}_{\mathrm{e}}$ for the adsorption of reactive orange 4 dye on polyaniline nano composite are summarized in Table-2. The pseudo first-order kinetic model of Lagergren does not fit well with the experimental data over the whole range of initial concentrations studied. The pseudo second-order kinetic equation is expressed $\operatorname{as}^{24}$

$$
\frac{\mathrm{t}}{\mathrm{q}_{\mathrm{t}}}=\frac{1}{\mathrm{k}_{2} \mathrm{q}_{\mathrm{e}}^{2}}+\frac{\mathrm{t}}{\mathrm{q}_{\mathrm{e}}}
$$

where, $\mathrm{k}_{2}$ is the rate constant of pseudo second-order adsorption $\left(\mathrm{g} / \mathrm{mg} \mathrm{min}\right.$ ) and $\mathrm{q}_{\mathrm{e}}$ is the equilibrium adsorption capacity $(\mathrm{mg} / \mathrm{g})$.

Fig. 5 shows the pseudo second -order plot for the adsorption of reactive orange 4 dye by polyaniline nano composite at various initial dye concentrations (temperature $30{ }^{\circ} \mathrm{C}$ ). A plot of $\mathrm{t} / \mathrm{q}_{\mathrm{t}}$ against $\mathrm{t}$ should give a linear relationship from which and $\mathrm{q}_{\mathrm{e}}$ can be determined from the intercept and slope of the plot. The correlation coefficient values are greater than 0.99 (Table-2) and the data points give a linear straight line. It indicates that the adsorption of reactive orange 4 dye by polyaniline nano composite follow the pseudo second order kinetic model.

Equilibrium adsorption isotherm: The Langmuir adsorption isotherm has been used successfully for many adsorption processes of monolayer adsorption. Langmuir mode $l^{25}$ is represented by the following equation:

$$
\frac{\mathrm{C}_{\mathrm{e}}}{\mathrm{q}_{\mathrm{e}}}=\frac{1}{\mathrm{Q}_{\mathrm{o}} \mathrm{b}_{\mathrm{L}}}+\left(\frac{1}{\mathrm{Q}_{\mathrm{o}}}\right) \mathrm{C}_{\mathrm{e}}
$$

\begin{tabular}{|c|c|c|c|c|c|c|c|c|}
\hline \multirow{2}{*}{ Parameter } & \multicolumn{4}{|c|}{ Initial dye concentration $(\mathrm{mg} / \mathrm{L})$} & \multicolumn{4}{|c|}{ Temperature $\left({ }^{\circ} \mathrm{C}\right)$} \\
\hline & 25 & 50 & 75 & 100 & 30 & 40 & 45 & 50 \\
\hline $\mathrm{q}_{\mathrm{e}} \exp (\mathrm{mg} / \mathrm{g})$ & 45.83 & 87.76 & 125.81 & 143.59 & 87.76 & 91.84 & 93.88 & 97.96 \\
\hline \multicolumn{9}{|c|}{ Pseudo first order kinetics } \\
\hline $\mathrm{k}_{1} \times 10^{-2}\left(\min ^{-1}\right)$ & 5.34 & 6.56 & 7.14 & 7.42 & 6.56 & 6.61 & 6.68 & 6.70 \\
\hline $\mathrm{q}_{\mathrm{e}} \mathrm{cal}(\mathrm{mg} / \mathrm{g})$ & 35.74 & 94.30 & 148.66 & 181.13 & 94.30 & 101.79 & 95.08 & 93.37 \\
\hline$r^{2}$ & 0.9324 & 0.9163 & 0.9013 & 0.9029 & 0.9163 & 0.9077 & 0.9241 & 0.9169 \\
\hline \multicolumn{9}{|c|}{ Pseudo second order kinetics } \\
\hline $\mathrm{k}_{2} \times 10^{-4}(\mathrm{~g} / \mathrm{mg} \min )$ & 14.82 & 5.30 & 3.56 & 2.95 & 5.30 & 5.39 & 5.85 & 6.69 \\
\hline $\mathrm{h}$ & 4.3783 & 6.4061 & 8.9606 & 9.7656 & 6.4061 & 6.9638 & 7.7340 & 9.0416 \\
\hline $\mathrm{q}_{\mathrm{e}} \mathrm{cal}(\mathrm{mg} / \mathrm{g})$ & 54.35 & 109.89 & 158.73 & 181.82 & 109.89 & 113.64 & 114.94 & 116.28 \\
\hline$r^{2}$ & 0.9963 & 0.9942 & 0.9925 & 0.9918 & 0.9942 & 0.9926 & 0.9935 & 0.9946 \\
\hline
\end{tabular}

TABLE-2

KINETIC PARAMETERS FOR THE ADSORPTION OF REACTIVE ORANGE 4 ONTO POLYANILINE NANO COMPOSITE 


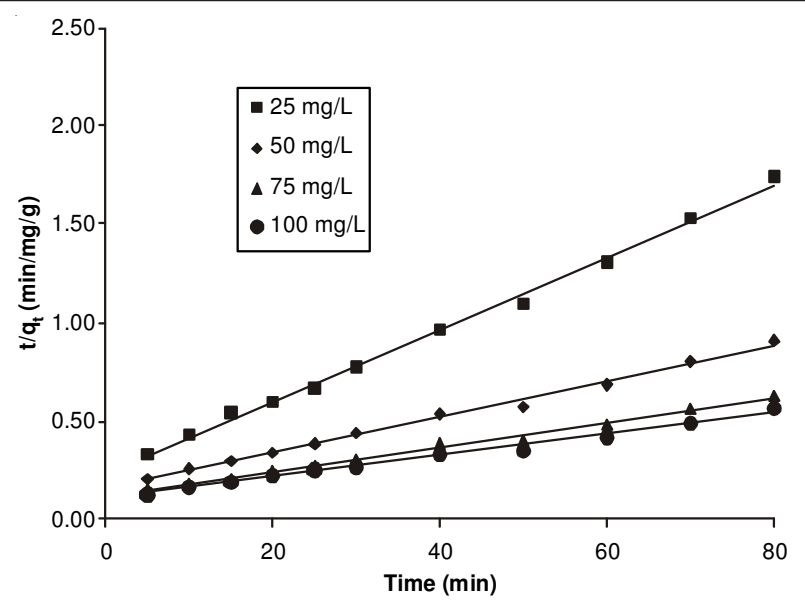

Fig. 5. Pseudo second order plot for the adsorption of reactive orange 4 onto polyaniline nano composite at $30^{\circ} \mathrm{C}$ (adsorbent dosage, 100 $\mathrm{mg} ; \mathrm{pH}, 4.1$ )

where, $\mathrm{Q}_{0}$ is the monolayer adsorption capacity $(\mathrm{mg} / \mathrm{g})$ and $\mathrm{b}_{\mathrm{L}}$ is Langmuir constant related to energy of adsorption.

Fig. 6 shows a linear plot of $\mathrm{C}_{\mathrm{e}} / \mathrm{q}_{\mathrm{e}}$ against $\mathrm{C}_{\mathrm{e}}$ for the removal of reactive orange 4 by polyaniline nano composite. The Langmuir adsorption capacity varies from $161.29 \mathrm{mg} / \mathrm{g}$ to $200 \mathrm{mg} / \mathrm{g}$ for the adsorption of reactive orange 4 onto polyaniline nano composite with increase in temperature from 30 to $45^{\circ} \mathrm{C}$. This indicates that the adsorption is favoured at high operating temperature. Similar results were reported for the adsorption of reactive brilliant red HE-3B by activated charcoal $^{26}$. The Langmuir isotherm fits quite well with the experimental data with good correlation coefficient as shown in Table-3.

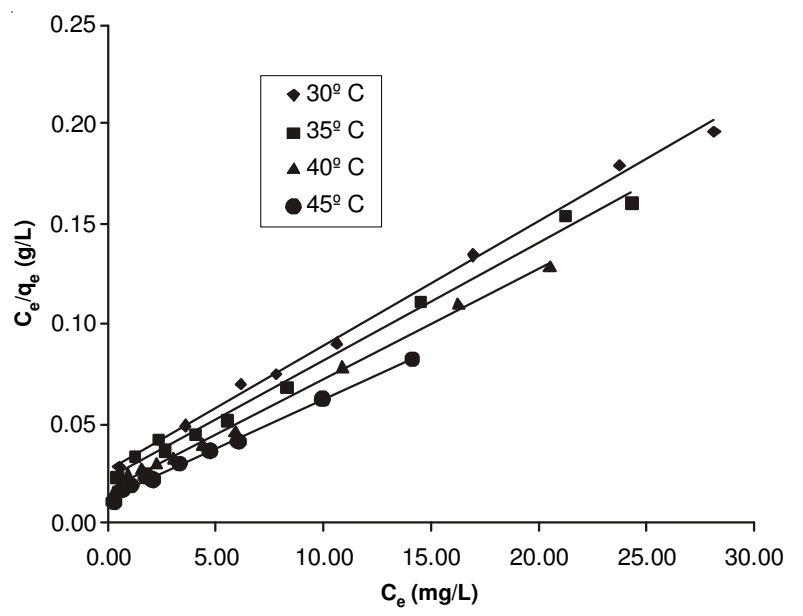

Fig. 6. Langmuir adsorption isotherm plot for the adsorption of reactive orange 4 dye onto polyaniline nano composite (adsorbent dosage, 100 mg; pH, 4.1; agitation time, $100 \mathrm{~min}$ )
The separation factor $\mathrm{R}_{\mathrm{L}}$ is calculated by the following equation to confirm the favourability of the adsorption process ${ }^{27}$.

$$
\mathrm{R}_{\mathrm{L}}=1 /\left(1+\mathrm{b}_{\mathrm{L}} \cdot \mathrm{C}_{0}\right)
$$

The values of $\mathrm{R}_{\mathrm{L}}$ found to be between 0 and 1 and confirm that the adsorption process is favourable.

The Freundlich isotherm is an empirical relationship describing the sorption of solutes from a liquid to a solid surface. Freundlich ${ }^{28}$ model is expressed as

$$
\log \mathrm{q}_{\mathrm{e}}=\log \mathrm{k}_{\mathrm{f}}+\frac{1}{\mathrm{n}} \log \mathrm{C}_{\mathrm{e}}
$$

A plot of $\log \mathrm{q}_{\mathrm{e}}$ versus $\log \mathrm{C}_{\mathrm{e}}$ gives a linear line with a slope of $1 / \mathrm{n}$ and intercept of $\log \mathrm{k}_{\mathrm{f}}$ and the results are given in Table-3. From the experimental data, $\mathrm{k}_{\mathrm{f}}$ values increased with increasing temperature for reactive orange 4, implying that the adsorption process may be endothermic in nature. Values $\mathrm{n}>1$ represent a favourable adsorption condition. The correlation coefficient values are poor compared to the Langmuir isotherm model.

The Dubinin-Raduskevich (D-R) isotherm describes the adsorption on a single uniform pore. Dubinin-Raduskevich isotherm ${ }^{29}$ is generally expressed as follows:

$$
\mathrm{q}_{\mathrm{e}}=\mathrm{q}_{\mathrm{D}} \cdot \mathrm{e}^{-\mathrm{B} \varepsilon^{2}}
$$

The linear form of $\mathrm{D}-\mathrm{R}$ isotherm equation is represented as:

$$
\begin{gathered}
\ln \mathrm{q}_{\mathrm{e}}=\ln \mathrm{q}_{\mathrm{D}}-\mathrm{B} \varepsilon^{2} \\
\varepsilon=\mathrm{RT} \ln \left(1+\frac{1}{\mathrm{C}_{\mathrm{e}}}\right)
\end{gathered}
$$

where, $\mathrm{q}_{\mathrm{D}}$ is the theoretical saturation capacity ( $\left.\mathrm{mol} / \mathrm{g}\right), \mathrm{B}$ is a constant related to the mean free energy of adsorption per mole of the adsorbate $\left(\mathrm{mol}^{2} / \mathrm{J}^{2}\right), \varepsilon$ is the Polanyi potential, $\mathrm{R}(\mathrm{J} / \mathrm{mol} / \mathrm{K})$ is the gas constant and $\mathrm{T}(\mathrm{K})$ is the absolute temperature. The $\mathrm{D}-\mathrm{R}$ constants $\mathrm{q}_{\mathrm{D}}$ and $\mathrm{B}$ were calculated from the linear plots of $\ln \mathrm{q}_{\mathrm{e}}$ versus $\varepsilon^{2}$ (figure not shown) are given in Table-3. The constant $\mathrm{B}$ gives an idea about the mean free energy $\mathrm{E}(\mathrm{kJ} /$ mol) of adsorption per molecule of the adsorbate when it is transferred to the surface of the solid from infinity in the solution and can be calculated from the following relationship ${ }^{30}$ :

$$
\mathrm{E}=1 /(2 \mathrm{~B})^{1 / 2}
$$

The adsorption is physisorption if the energy of activation is in the range of $5-40 \mathrm{~kJ} / \mathrm{mol}$ and chemisorption if the energy of activation is between $40-800 \mathrm{~kJ} / \mathrm{mol}$. The results from Table3 suggest that the adsorption of reactive orange 4 by polyaniline nano composite is physisorption in nature. D-R isotherm is not able to describe the experimental data properly because of

\begin{tabular}{|c|c|c|c|c|c|c|c|c|c|}
\hline \multirow{2}{*}{$\begin{array}{c}\text { Temperature } \\
\left({ }^{\circ} \mathrm{C}\right)\end{array}$} & \multicolumn{3}{|c|}{ Langmuir isotherm } & \multicolumn{3}{|c|}{ Freundlich isotherm } & \multicolumn{3}{|c|}{ D- $R$ isotherm } \\
\hline & $\mathrm{Q}_{0}(\mathrm{mg} / \mathrm{g})$ & $\mathrm{b}_{\mathrm{L}}(\mathrm{L} / \mathrm{mg})$ & $r^{2}$ & $\mathrm{n}$ & $\left(\mathrm{mg}^{1-1 / \mathrm{n}} \mathrm{L}^{1 / \mathrm{n}} \mathrm{g}^{-1}\right)$ & $r^{2}$ & $\mathrm{q}_{\mathrm{D}}(\mathrm{mg} / \mathrm{g})$ & $\mathrm{E}(\mathrm{kJ} / \mathrm{mol})$ & $r^{2}$ \\
\hline 30 & 161.29 & 0.2305 & 0.9969 & 2.05 & 33.2659 & 0.9472 & 102.843 & 1.29 & 0.8167 \\
\hline 35 & 169.49 & 0.2682 & 0.9926 & 2.01 & 37.0169 & 0.9225 & 104.752 & 1.581 & 0.7656 \\
\hline 40 & 178.57 & 0.3457 & 0.9962 & 2.03 & 44.2588 & 0.9372 & 108.777 & 2.236 & 0.7571 \\
\hline 45 & 200.00 & 0.4065 & 0.9965 & 1.88 & 52.9785 & 0.9594 & 117.601 & 2.236 & 0.7976 \\
\hline
\end{tabular}
the poor linear correlation coefficient for the adsorption of the dye onto polyaniline nano composite at different temperatures.

TABLE-3

ISOTHERM CONSTANTS FOR THE ADSORPTION OF REACTIVE ORANGE 4 DYE ONTO POLYANILINE NANO COMPOSITE AT VARIOUS TEMPERATURES 
Thermodynamics study: Langmuir isotherm equation was applied to calculate the thermodynamic parameters as follows:

$$
\begin{gathered}
\Delta \mathrm{G}^{\circ}=-\mathrm{RT} \ln \mathrm{k}_{\mathrm{L}} \\
\ln \mathrm{k}_{\mathrm{L}}=\frac{\Delta \mathrm{S}^{\circ}}{\mathrm{R}}-\frac{\Delta \mathrm{H}^{\circ}}{\mathrm{R}} \frac{1}{\mathrm{~T}}
\end{gathered}
$$

where, $\mathrm{k}_{\mathrm{L}}$ is the Langmuir equilibrium constant, $\Delta \mathrm{H}^{\mathrm{o}}$ and $\Delta \mathrm{S}^{\mathrm{o}}$ is the standard enthalpy and entropy changes of adsorption respectively.

Thermodynamic parameters like $\Delta \mathrm{H}^{\mathrm{o}}, \Delta \mathrm{S}^{\mathrm{o}}$ and $\Delta \mathrm{G}^{\mathrm{o}}$ were determined from the slope and intercept of van't Hoff's plot of $\ln \mathrm{k}_{\mathrm{L}}$ versus $1 / \mathrm{T}$ (figure not shown). Table-4 shows the thermodynamic results for the removal of reactive orange 4 by polyaniline nano composite. The decrease in the negative values of $\Delta \mathrm{G}^{\circ}$ with an increase in temperature (30 to $45^{\circ} \mathrm{C}$ ) indicates that the adsorption becomes more favourable at high temperature. The positive $\Delta \mathrm{H}^{\circ}$ values indicate that the adsorption of reactive dye onto polyaniline nano composite is endothermic process. Furthermore the positive $\Delta S^{\circ}$ indicates that the degrees of freedom increased at the solid-liquid interface during adsorption of reactive dye onto polyaniline nano composite. Generally, $\Delta \mathrm{G}^{\mathrm{o}}$ for physisorption is between -20 to $0 \mathrm{~kJ} / \mathrm{mol}$ and for chemisorption is between -80 to -400 $\mathrm{kJ} / \mathrm{mol}^{31}$. The $\Delta \mathrm{G}^{\mathrm{o}}$ values from Table-4 confirm that the adsorption of reactive orange 4 by polyaniline nano composite

\begin{tabular}{|c|c|c|c|}
\hline \multicolumn{4}{|c|}{$\begin{array}{c}\text { TABLE-4 } \\
\text { THERMODYNAMICAL PARAMETERS FOR THE } \\
\text { ADSORPTION OF REACTIVE ORANGE } 4 \text { ONTO } \\
\text { POLYANILINE NANO COMPOSITE }\end{array}$} \\
\hline Temperature $\left({ }^{\circ} \mathrm{C}\right)$ & $\Delta \mathrm{H}^{\circ}(\mathrm{kJ} / \mathrm{mol})$ & $\Delta S^{\circ}(\mathrm{kJ} / \mathrm{K} / \mathrm{mol})$ & $\Delta \mathrm{G}^{\circ}(\mathrm{kJ} / \mathrm{mol})$ \\
\hline 30 & \multirow{4}{*}{42.2493} & \multirow{4}{*}{0.1693} & -9.0486 \\
\hline 35 & & & -9.8951 \\
\hline 40 & & & -10.7416 \\
\hline 45 & & & -11.5881 \\
\hline
\end{tabular}
is physisorption in nature.

The pseudo second order rate constant $\mathrm{K}_{2}$ of the dye adsorption is expressed as a function of temperature by Arrhenius relationship using the equation:

$$
\ln \mathrm{k}_{2}=\ln \mathrm{A}-\frac{\mathrm{E}_{\mathrm{a}}}{\mathrm{RT}}
$$

The value of $\mathrm{E}_{\mathrm{a}}$ is calculated as $12.444 \mathrm{~kJ} / \mathrm{mol}$ from the slope of a plot of $\ln \mathrm{k}_{2}$ versus $1 / \mathrm{T}$ (figure not shown). This confirmed that physisorption is predominantly operating force along with very weak chemical forces of attraction.

Desorption studies: Maximum desorption of $78.6 \%$ for reactive orange 4 dye was observed at a $\mathrm{pH}$ range of 8 to 9 . Desorption of reactive dye from polyaniline nano composite using alkaline solution may imply that physisorption mechanism of the anionic dye molecules along with weak chemical forces of attraction onto polyaniline nano composite.

\section{Conclusion}

In this present study, polyaniline nano composite was easily synthesized by chemical oxidation method directly on the surface of sawdust of Thevetia peruviana and used for the removal of reactive orange 4 from aqueous solutions. Removal of reactive orange 4 is $\mathrm{pH}$ dependent and the maximum removal was attained when $\mathrm{pH}$ was below 5 . The adsorption of the dyes increased with increase in temperature from 30 to $45^{\circ} \mathrm{C}$ indicates that the adsorption is endothermic in nature, which was well supported by positive $\Delta \mathrm{H}^{\mathrm{o}}$ values. Kinetic studies showed that adsorption of reactive orange 4 followed pseudosecond order model. The data obtained from adsorption isotherms are well fitted with Langmuir model which suggests the monolayer coverage of the dyes on surfaces of polyaniline nano composite. The Langmuir adsorption capacity varies from 161.29 to $200 \mathrm{mg} / \mathrm{g}$ for reactive orange 4 onto polyaniline nano composite with increase in temperature from 30 to $45^{\circ} \mathrm{C}$. The negative values obtained from van't Hoff plots confirmed that the adsorption of reactive dye (reactive orange 4) is spontaneous in nature. The results showed that polyaniline nano composite can be used as a potential adsorbent for the removal of reactive dye, reactive orange 4 from aqueous solutions.

\section{ACKNOWLEDGEMENTS}

The second (PNP) and third (PS) authors gratefully acknowledged the financial support given by the University Grants Commission (UGC), New Delhi under the Major research project scheme to carry out this research project.

\section{REFERENCES}

1. G. Crini, Bioresour. Technol., 97, 1061 (2006).

2. Y.M. Slokar and M.Le Marechal, Dyes Pigments, 37, 335 (1998).

3. J. Wu, M.A. Eitman and S.E. Law, J. Environ. Eng., 12, 272 (1998).

4. N. Bairagi, M.L. Gulrajani, B.L. Deopura and A. Shrivastava, Colorat. Technol., 121, 113 (2005).

5. J.M. Chern and S.N. Huang, Ind. Eng. Chem. Res., 37, 253 (1998).

6. O. Gercel, A. Ozcan, A.S. Ozcan and H.F. Gercel, J. Environ. Eng., 135, 333 (2009).

7. T. Robinson, G. Mcmullan, R. Marchant and P. Nigam, Bioresour. Technol., 77, 247 (2001).

8. S.V. Mohan, N.C. Rao and J. Karthikeyan, J. Hazard. Mater, 90, 189 (2002).

9. D. Mohan, K.P. Singh, G. Singh and K. Kumar, Ind. Eng. Chem. Res., 41, 3688 (2002).

10. F.E. Okieimen, C.O. Okieimen and R.A. Wuana, J. Chem. Soc. Nigeria, 32, 126 (2007)

11. G. Mckay, Adsorption, 4, 361 (1998).

12. B.S. Girgis and A.A. EI-Hendawy, Micropor. Mesopor. Mater, 52, 105 (2002).

13. A. Aygun, S. Yenisoy-karakas and I. Duman, Micropor. Mater, 66, 189 (2003).

14. R. Ansari and Z. Mosayebzadeh, Iran. Polym. J., 19, 541 (2010).

15. ISI, Activated Carbon, Bureau of Indian Standards, New Delhi, IS 877 (1989).

16. American Society for Testing Materials (ASTM), D4607-94 (1980).

17. A. Habib, Z. Hasan, A.S.M.S. Rahman and A.M.S. Aslam, Pak. J. Anal. Environ. Chem., 7, 112 (2006).

18. M.S. Baei, V. Babaee and F. Pirouz, 2nd International Conference on Chemistry and Chemical Engineering, IPCBEE 14, Singapore, 14, 95 (2011).

19. M.C. Ncibi, B. Mahjoub and M. Steffen, Int. J. Environ. Sci. Tech., 4, 433 (2007).

20. V.K. Konaganti, R. Kota, S. Patil and G. Madras, Chem. Eng. J., 158, 393 (2010).

21. V. Jaikumar, K.S. Kumar and D.G. Prakash, Int. J. Appl. Sci. Eng., 7, 115 (2009).

22. S.A. Alzaydien and W. Manasreh, Int. J. Phys. Sci., 4, 172 (2009).

23. S. Lagergran, Svenska Ventenskapsakade-miemns, Handlingar Band, 24, 1 (1898).

24. Y.S. Ho and G. Mckay, Wat er Res., 34, 735 (2000).

25. I. Langmuir, J. Am. Chem. Soc., 38, 2221 (1916).

26. D. Suteu and D. Bilba, Acta Chim. Slov., 52, 73 (2005).

27. U. Filipkowska, E. Klimiuk, S. Grabowski and E. Siedlecka, Polish J. Environ. Studies, 11, 315 (2002).

28. H.M.F. Freundlich, J. Phys. Chem., 57A, 385 (1906).

29. R. Subha and C. Namasivayam, Indian J. Chem. Tech., 16, 471 (2009).

30. C.-Y. Kuo, C.-H. Wu and J.-Y. Wu, J. Colloid. Interface Sci., 327, 308 (2008).

31. M.J. Jaycock and C.D. Parfitt, Ellis Horwood Ltd., Chichester (1981). 